\title{
Endoscopic Decompression in Colonic Distension
}

\author{
Sebastian Belle \\ Department of Internal Medicine II, University Medical Center Mannheim, Medical Faculty Mannheim, \\ Heidelberg University, Mannheim, Germany
}

\section{Keywords}

Acute colonic pseudo-obstruction - Malignant colorectal stenosis · Tube decompression · Self-expandable metallic stent

\begin{abstract}
Background: Acute colonic distension is a medical emergency with high morbidity and mortality. Clinically important causes of colonic distension are acute colonic pseudo-obstruction, colonic volvulus, and malignant obstruction. Endoscopic decompression is one established therapeutic strategy. Summary: This therapeutic review will give an overview of possible therapeutic strategies based on the recently published literature, focusing on endoscopic decompression and summarizing the other therapeutic possibilities. The review discusses separately the therapeutic options of acute colonic pseudo-obstruction, colonic volvulus, and malignant obstruction, providing an evidence-based orientation for clinical use. Key Messages: Endoscopic decompression of colonic distension is an established therapy with high clinical success. The technique and its position in the therapy sequence differ depending on the medical condition, the trigger of the colonic distension, and the local expertise.
\end{abstract}

(c) 2021 S. Karger AG, Basel

\section{Introduction}

Acute colonic distension is the result of an ongoing motility disorder vitally threatening the patient. While the origin of colonic distension can be either obstructive or non-obstructive, the common final pathological path is the same. The distension of the colon wall is analogue to the Laplace law, to a rising wall tension intensified in the cecum, since the wall thickness is the denominator in the Laplace law and is in the cecum $<0.5 \mathrm{~mm}$. The increased wall tension leads to ischemia, bacterial translocation, and perforation.

Acute colonic distension needs a concentrated and consequent workup and treatment by the involved physicians, since time is an important factor determining therapeutic success. The patient is often in a poor medical condition and several different medical disciplines are involved: radiologist, gastroenterologists, surgeons, and anesthetists. Urgent therapy is crucial, as this is a timecritical medical condition with the need for good intraprofessional cooperation requiring a comprehensive clinical pathway. This therapeutic review aims to discuss the current key data for evidence-based decisions in endoscopic decompression in colonic distension focusing on the common medical conditions. It may be a starting point for individual clinical pathways which have to be based on individual expertise in the different fields of therapy in each individual hospital.

\section{Etiology, Pathogenesis, and Epidemiology}

Non-obstructive colonic distension with acute onset is best described as acute colonic pseudo-obstruction (ACPO). The definition of the ACPO is acute colonic distension without mechanical obstruction or an extrinsic inflammatory process. Several overlapping terms have been used and are still used, such as acute intestinal pseudo obstruction, Ogilvie's syndrome, pseudo-megacolon, adynamic ileus, paralytic ileus, functional obstruction of the intestinal tract, cecal ileus, and many more. Different nam- 
Table 1. Predisposing factors for ACPO

\begin{tabular}{ll}
\hline Medical category & Risk factors \\
\hline Metabolism & Diabetes \\
& Electrolyte imbalance \\
& Renal failure \\
& Hepatic failure \\
\hline Medication & Opiates \\
& Tricyclic antidepressants \\
& Clonidine \\
& Anti-Parkinson agents \\
& Cytotoxic chemotherapy \\
& Calcium channel antagonists \\
& Anticholinergics \\
& Hypothyroidism \\
\hline Surgery & Cardiac surgery \\
& Abdominal surgery \\
& Major orthopedic surgery \\
& Spine surgery \\
& Gynecologic surgery \\
& Urologic surgery \\
& Normal vaginal delivery \\
Caesarean section \\
Pre-eclampsia \\
\hline Obstetric & Chronic obstructive pulmonary disease \\
& Myocardial infarction \\
& Congestive heart failure \\
& Sepsis \\
\hline Cardiorespiratory & \\
\hline
\end{tabular}

ing and inconsistencies in the definition of the disease are part of the problem in the research and reporting of ACPO.

The mechanism of ACPO is not fully understood and seems to be multifactorial. There are several risk factors predisposing for ACPO from such different medical fields as metabolism, the cardio-respiratory system, or obstetric and gynecological diseases, as shown in Table 1.

Central but not exclusive to the etiology is an imbalance of the sympathetic and parasympathetic activation, leading to a relative deficiency of the parasympathetic activation and as a result to an atonic colonic segment [1]. The atonic colonic muscularis leads to a passive distension of the colon [2]. Observations that are associated with this are: the dilatated part of the colon in ACPO often begins in the splenic flexure and the splenic flexure marks the transition zone between the parasympathetic innervation of the mid-gut from the vagus nerve and the innervation of the hind-gut by the sacral parasympathetic nerves (S2-4), patients with ACPO are often in a deteriorated health condition before the onset of ACPO, and as a result have systemic sympathetic activation. This is in line with the fact that parasympathetic therapy plays an important role in the therapy of ACPO $[3,4]$.

Although the true incidence remains unknown, in a retrospective cohort study using a national admissions database in the USA, the annual incidence of ACPO was approximately 100 cases of 100,000 inpatient admissions per year with a slight increase in incidence over the years based on data from the 1998 to 2011 [5]. In published cohorts the mean age is 64-74 years, with females being younger since caesarian is a predisposing factor. Up to $86-90 \%$ of the patients have concomitant diseases $[6,7]$.

Acute obstructive colonic distension is mainly caused by malignant stenosis either directly by the tumor or as a consequence of peritoneal carcinosis. Symptomatic malignant colorectal stenosis is caused by colorectal cancer in $75 \%$ of patients. Acute obstructive colonic distension due to colorectal cancer occurs in $8-13 \%$ of patients $[8,9]$.

\section{Therapy}

With colonic endoscopic decompression via an endoscope or with the additional placement of a tube or a selfexpandable metallic stent (SEMS), there are several endoscopic possibilities. The difficulty is to decide when to use which technique - the therapeutic window is small, and each technique has its own risk profile. In some cases, conservative measures or medication therapy are sufficient and endoscopic therapy just adds to the risk. On the other hand, there are lost cases where the intervention is too late, and surgery is the only option.

Being "too late for intervention" is a common scenario. If there is a clinical or radiological sign of perforation or transmural ischemia, endoscopic intervention is no use. The more difficult scenarios to define are discussed later in the paper.

The important first step for therapeutic decisions is the diagnostic workup. Therapy options differ if the origin of the colonic distension is obstructive or non-obstructive. Abdominal cross-sectional imaging with $\mathrm{CT}$ is used to identify differences in the 2 etiologies and to detect signs of perforation, while an abdominal X-ray is sufficient for serial assessment of the colonic diameter [10]. Anamnesis, including medical history, as well as medication are very important since they play a vital role in functional colonic distension, and as an initial step in the physical examination to detect peritonitis and signs of perforation.

\section{Non-Obstructive Colonic Distension}

Differentiating ACPO from severe inflammatory colitis in inflammatory bowel disease, ischemic colitis or toxic megacolon, and chronic intestinal pseudo-obstruction is important [2]. ACPO is associated with spontaneous perforation in $3-25 \%$ and up to $50 \%$ mortality in cases of a perforation [10]. 
The typical presentation on CT is distension of the right colon without distension of the rectum and a relatively normal appearance of the small bowel. This presentation is neither pathognomonic nor essential for the diagnosis of ACPO [11].

Without treatment in $3-15 \%$ of cases, spontaneous perforation has been reported with a mortality rate estimated at $50 \%$ or higher [12]. While there is no causal therapy for ACPO, it is important to optimize factors with known influence on the gastrointestinal motility. The patient-associated factors that can be corrected include electrolyte imbalance, renal insufficiency, hypothyroidism, and infection [13]. It is also important to check therapy-associated factors interacting with colonic motility as morphine derivates, anticholinergics, and calciumchannel antagonists.

The first therapeutic step in ACPO includes: conservative therapy, discontinuation of narcotics, anticholinergics, and calcium-channel antagonists; correction of electrolyte abnormalities; nil per os; decompressing the GI tract by nasogastric tube and/or rectal tube insertion, and frequent position changes [7]. The second therapeutic step is active treatment. There are 2 established therapies: endoscopic decompression and medication with neostigmine. There are 2 relevant prognostic markers for mortality in ACPO: size and delayed decompression. In a pooled literature review and retrospective analysis of $400 \mathrm{pa}-$ tients, Vanek and Al-Salti [4] could correlate the cecum diameter and time to compression with morbidity and mortality. A diameter $\geq 12 \mathrm{~cm}$ was associated with a mortality of $7 \%$, which doubled to $14 \%$ with a diameter $>14$ $\mathrm{cm}$. A short duration of colon dilatation $<4$ days showed a mortality of $15 \%$, while a delay of $>7$ days before decompression had a mortality of $73 \%$. Johnson et al. [14] retrospectively evaluated plain abdominal radiographs of 46 patients with a cecal distension $>10 \mathrm{~cm}$. In this mixed cohort $81 \%$ of patients had a non-obstructive colonic distension. No patient with $\leq 4$ days of distension had a perforation. The overall perforation rate was $15 \%$ and most of the patients with perforation had $\geq 6$ days of colonic distension. The European Society of Gastrointestinal Endoscopy (ESGE) guideline [13] and American Society for Gastrointestinal Endoscopy (ASGE) guidelines [10, 15] refer to the publications by Johnson et al. [14] and Vanek and Al-Salti [4] to define the starting point for active treatment as colonic distension $\geq 12 \mathrm{~cm}$ in the cecum and/ or $\geq 6$ days of colonic distension.

\section{Neostigmine}

Neostigmine is an anticholinesterase, a parasympathomimetic agent. In the therapy of ACPO, neostigmine is a treatment with proven efficiency with retrospective published data from 4 small prospective RCTs with a pooled patient number of 127 [16-19]. With a number needed to treat of 1 , the effectiveness of one dose in resolving ACPO is $89.2 \%$ [19]. Neostigmine has minor side effects and bradycardia as a threatening side effect, with 6.3-11\% experiencing symptomatic bradycardia [20]. The initial response to neostigmine in the randomized study was $94 \%$, with an $11 \%$ recurrence [16]. Unfortunately, relapse of ACPO after the initial response to pharmacologic or endoscopic therapy occurs in up to $40 \%$ of patients [21].

\section{Endoscopic Decompression}

The concept of endoscopic decompression is to reduce the colon diameter, to reduce wall tension, and to allow blood circulation and the neuronal and muscular system to restart peristaltic movement. This can be achieved by simple colonoscopy and decompression via the endoscope or with colonoscopy and endoscopically placing a trans-anal decompression tube. The clinical success of simple endoscopic decompression is up to $86 \%[11,22]$. The risk of perforation is $2 \%$ and of mortality is $1 \%$ in published cohorts, the recurrence of colonic distension without the use of a decompression tube is up to $40 \%$ [ 12 , $23,24]$. The published data have to be critically appraised, however, since there is probably a publication bias and most of the data come from tertiary centers with large intensive or intermediate care units and the possibility to gain expertise in endoscopic decompression therapy.

A published retrospectively analyzed cohort of 53 patients had clinical success in up to $92.5 \%$, with a decompression tube in addition to endoscopic decompression in $86 \%$. The complication rate was $3.8 \%$, including 1 perforation [25]. This is in line with several other published cohorts with a clinical success rate of $84-86 \%$ either after 1 or 2 colonoscopies $[4,26]$. Endoscopic decompression and neostigmine therapy in ACPO have a high clinical success with low complication rates; the difficult question is whom to treat with either therapy or in what sequence.

Ross et al. [5] analyzed a large national healthcare administrative data repository with ACPO patients accounting for an estimated $20 \%$ of all inpatient hospital admissions in the USA. Patients were grouped by treatment into 4 groups: medical management, colonoscopy alone, surgery alone, or surgery and colonoscopy. Increasing invasiveness was independently associated with higher odds of medical complications, procedural complications, and death $(p<0.0125)$, in the following sequence: medical management $<$ endoscopy $<$ surgery $<$ surgery and endoscopy, with overall high rates of medical complications (45.7\%), procedural complications (15.9\%), and mortality rates (7.7\%). This reflects, above 


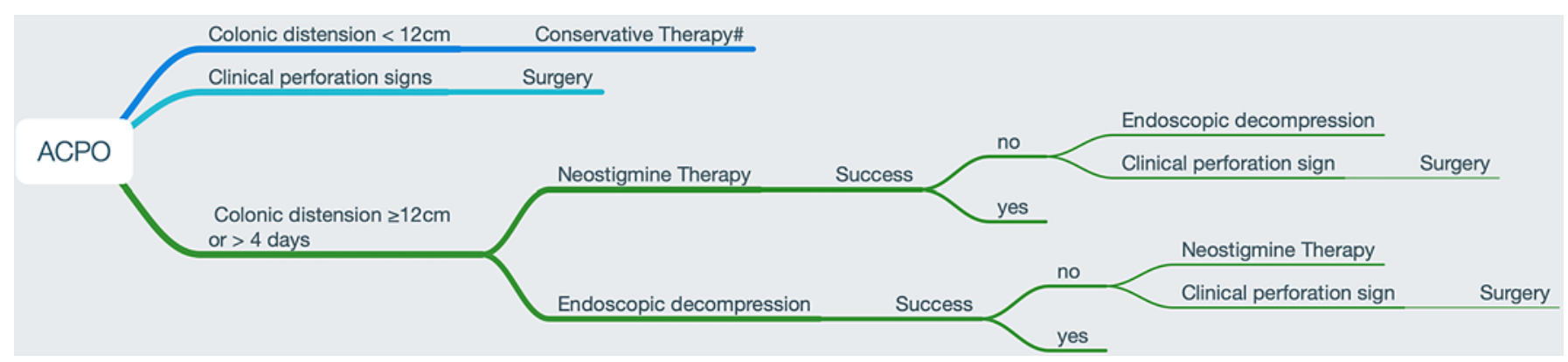

Fig. 1. Specific treatment for ACPO. ${ }^{*}$ Conservative treatment: discontinuation of narcotics, anticholinergics, and calcium-channel antagonists; correction of electrolyte abnormalities; nil per os; decompressing the GI tract by nasogastric tube and/or rectal tube insertion.

all, the differing severity of the medical conditions, but it also implies that it is important to establish a therapy strategy before surgery is necessary.

There are no published randomized studies comparing neostigmine with colonoscopic decompression. Peker et al. [22] compared retrospective patients who underwent colonoscopic decompression because they had a poor first response to neostigmine treatment with patients who had a poor first response to colonoscopic decompression and subsequently received neostigmine. The endpoint was the success of disease management. The authors concluded that colonoscopic decompression as a first-line treatment option was more effective as an initial therapy and was more effective at avoiding a second treatment modality. The data have to be interpreted in the context of the analyzed cohort since 2 different time periods were compared, from 2008 to 2011 neostigmine after conservative therapy was the standard, and from 2011 to 2015 decompression colonoscopy was used as the first-line treatment. This could bias the data since several other factors not accounted for could influence the results.

Since there are no head to head randomized data and little overall data comparing both, neostigmine is often used in the first therapeutic step and, if there is no clinical success, endoscopic decompression is used. This is justified, since neostigmine has only minor side effects, and bradycardia, as a relevant side effect, is manageable on an intermediate care unit or intensive care unit, where most of the patients are if there is the need for active treatment. It is important to move to the next therapeutic step without a time delay if neostigmine is not leading to clinical success. The ESGE recommends prompt endoscopic decompression if the cecal diameter is $>12 \mathrm{~cm}$ and if the ACPO exists for a duration of longer than 4-6 days [13], to account for the higher risk for perforation with a longer duration of ACPO. Figure 1 summarizes the established therapy for ACPO in a flow chart. While the evidence is of low quality, it can serve as common ground for the involved medical disciplines in the local hospital.

\section{Volvulus}

The definition of colonic volvulus is the torsion of a colonic segment along its mesenteric axis. Volvulus leads to oral distension and is consecutive with ischemia; predisposition points are the sigmoid colon and the cecum. Volvulus is diagnosed by CT and endoscopy is therapeutic and diagnostic in assessing the viability of the mucosa [27]. If there is no clinical sign of perforation, the first-line therapy of sigmoid volvulus is endoscopic detorsion with a resolution of the volvulus in $60-95 \%$ [27]. Although there are no randomized data on the insertion of the sigmoidal tube, it seems to stabilize the success, but recurrence is as high as $90 \%$ if the therapy is only endoscopic. Endoscopic resolution of sigmoid volvulus should be followed by surgical resection, while in cecal volvulus, primary surgery therapy is indicated, as endoscopic therapy has a lower success rate and ischemia is more often present [28].

\section{Obstructive Colonic Distension}

\section{Malignant Stenosis}

Symptomatic malignant colorectal stenosis requires an emergency intervention for the decompression of the colon. Symptomatic malignant colorectal stenosis is caused by colorectal cancer in $75 \%$ of patients. In acute colonic obstruction patients are in a poor condition, and emergency surgery in comparison to elective colon cancer resection has a higher mortality rate (19 vs. $9 \%)$ and a lower 5-year survival rate (19 vs. 37\%) [29]. Higher anastomotic leakage rates lead to a higher rate of preventive ostomy and also a higher permanent ostomy rate. There are 2 endoscopic techniques to avoid emergency surgery: decompression tubes or SEMS as a bridge to elective surgery. 


\section{Self-Expandable Metallic Stent}

\section{Left-Sided Colonic Obstruction}

Left-sided colonic obstruction is more frequent since left-sided colon cancer is more frequent. This is important, as published data mostly refer to left-sided colon cancer, often excluding distal rectal cancer. Stenting for rectal cancer is often not a good indication because the stent is not well tolerated, as stents in the rectum are symptomatic with pain and incontinence and have high rates of dislocation.

In a systematic review, Watt et al. [30] reported a median technical success rate of $96.2 \%$, ranging from 66.6 to $100 \%$, and a median rate of clinical success of $92 \%$, ranging from 46 to $100 \%$. As for the safety aspects, the median rate of migration was $11 \%$, ranging from 0 to $50 \%$, and the median rate of perforation by guidewire or stent was $4.5 \%$, ranging from 0 to $83 \%$.

A recently published systematic review and meta-analysis by Arezzo et al. [31] in left-sided malignant colonic obstruction compared emergency surgery to SEMS as a bridge to surgery. The paper included 8 randomized trials with 497 patients in total. The authors could show a lower overall morbidity within 60 days for SEMS (33.9 vs. $51.2 \%$; RR 0.59; $p=0.023)$, a lower temporary stoma rate with SEMS (33.9 vs. 51.4\%; RR 0.67; $p<0.001$ ), a lower permanent stoma rate with SEMS (22.2 vs. 35.2\%; RR $0.66 ; p=0.003)$, and the primary anastomosis was successful with SEMS in 70.0 vs. $54.1 \%$ of patients (RR 1.29; $p=0.043)$.

An issue discussed from the start was the oncological outcome of patients with an SEMS, since it was postulated that the pressure on the tumor could lead to microperforation and tumor dissemination, leaving alone the risk of an overt perforation with intra-abdominal tumor dissemination. Higher local recurrence and a lower disease-free survival (DFS) was shown in a randomized trial for patients with stent- or guidewire-related perforation [32]. In a systematic review comparing the long-term outcome of SEMS versus emergency surgery, with 5 randomized controlled trials, 3 prospective and 6 retrospective studies, there was no difference in the 3 - and 5-year survival rate, 5-year disease-free rate, overall recurrence rate, and local recurrence rate [23]. There were 2 other metaanalyses showing the same results, with no deterioration in key surrogate parameters of the oncological outcome of the patients with SEMS compared to emergency surgery $[33,34]$. Tamini et al. [35] made the next step, matching a retrospective elective colon resection group (not an emergency resection group) with a quasi-elective colon resection group with previous SEMS placement from a prospective data set, comparing their DFS rates. DFS and overall survival (OS) did not reach the median value after a mean follow-up of 54 months, but there was no signifi- cant difference in both groups, suggesting a benefit for the bridge to surgery concept beyond equivalence to emergency surgery. It is important for the interpretation that the cohort had a perforation rate of $3.8 \%$ in the SEMS group, and the patients were counted as "intention to treat" in the SEMS group. The authors discussed that higher perforation rates would probably have an impact on the therapeutic impact of SEMS placement. This could be shown in a systematic review and meta-analysis by Cao et al. [36] comparing SEMS with emergency surgery, in which 5-year DFS, 5-year OS, local recurrence, and overall recurrence rates were the same. However, the subgroup analysis showed a higher 5-year survival rate in studies with stent placement success of $\geq 95 \%$.

\section{Right-Sided Colonic Obstruction}

As stated previously, data on right-sided malignant obstruction are rare. A systematic review from 2015 compared emergency resection with SEMS in right-sided colonic obstruction and showed lower mortality (0 vs. $10.8 \%, p=0.009$ ), less major morbidity ( 0.8 vs. $23.9 \%$, $p=0.049$ ), and lower risk of anastomotic leakage (0 vs. 9.1\%) for patients with an SEMS [37].

SEMS in left-sided malignant colonic obstruction is a beneficial therapy with good short-term results and equivalent oncological long-term outcomes to emergency surgery. It even has initial promising results showing a better oncological outcome in comparison to emergency surgery, maybe showing an equivalent outcome to elective surgery. There are fewer data on right-sided malignant colonic obstruction, but the ESGE suggest consideration of colonic stenting in right-sided obstruction as a weak recommendation with low-quality evidence in their 2020 Guideline update of SEMS for obstructing colonic and extracolonic cancer [38]. An important factor for successful SEMS therapy is a high technical success rate, since perforation with the wire or the stent seems to have a decremental effect beyond the short-term complications. Therefore, it is important to use endoscopic and fluoroscopic guidance for deploying the stent, but, on the other hand, do not use stricture dilatation before or after stent placement since it increases the risk of perforation [39-41].

\section{Tube Decompression}

Besides decompression with SEMS, tube decompression is used in malignant obstruction.

\section{Right Side}

Suzuki et al. [42] compared patients with either SEMS or tube decompression for right-sided acute malignant colonic obstruction as bridging for surgery. In this retrospective single-institution study, the tube decompression showed better 5-year OS and DFS than the SEMS decom- 
pression (OS 79.5 vs. $32 \%, p=0.043$, HR 17.41; DFS 68.9 vs. $45.9 \%, p=0.032$, HR 14.56). Limiting the validity of the analysis in the tube group were 8 out of 23 patients with only a long trans-nasal tube. The trans-nasal tube is not used in this indication in Europe or in the USA. It is also questionable whether the patients with clinical improvement with only a long trans-nasal tube started from the same clinical condition as the patients with clinical improvement with SEMS or trans-anal decompression, as the decision process for either tube type is not described in the paper.

\section{Left Side}

As with SEMS, there are more data published on tube decompression of left-sided malignant obstruction. In a systematic review and meta-analysis, Xu et al. [43] summarized the data of 11 studies consisting of 3 randomized studies and 8 observational studies comparing the transanal tube with SEMS. The technical success rate between the 2 techniques did not differ significantly. Tube decompression showed a lower clinical success rate and higher complication rate than SEMS therapy. Using a fixed-effects model comparing the clinical success rate between tube decompression and SEMS, the OR was 0.31 (95\% CI $0.15-0.64, p=0.002$ ), and comparing complications between tube decompression and SEMS, the pooled OR was 2.11 (95\% CI 1.07-4.16, $p=0.03)$.

While there are published data for the use of tube decompression in right-sided malignant colonic obstruction, as in SEMS therapy in right-sided colonic obstruction, high-quality data are rare. Thus, one can only conclude that tube decompression is an option. For left-sided malignant colonic obstruction there is more evidence that tube decompression is an option, but the SEMS therapy is probably more clinically effective with lower complications.

\section{Palliative Setting}

A systematic review and meta-analysis by Ribeiro et al. [44] analyzed 4 randomized trials comparing SEMS versus emergency surgery in acute malignant colonic obstruction. Emergency surgery had a higher definitive stoma rate of 84 vs. $14.3 \%$ in the SEMS group; however, there was no difference in 30-day mortality, early complications, or mean survival.

\section{Conclusion}

Endoscopic decompression of colonic distension is an established therapy with high clinical success. The technique and its position in the therapy sequence differ depending on the medical condition and the trigger of the colonic distension.
In ACPO, before endoscopic decompression is used, all conservative measurements have to be exhausted. Endoscopic decompression is used if neostigmine was not clinically successful. Since colonoscopy alone has a high rate of recurrent distension, a trans-anal decompression tube should be used if there is no sign of ischemia.

Endoscopic decompression in sigmoid volvulus is often successful but has to be accompanied by elective surgery because of a high recurrence rate. Cecal volvulus has a lower endoscopic success rate and the standard therapy is surgery.

Malignant stenosis as the most common cause for obstructive colonic distension has several endoscopic therapy options; for example, therapy with SEMS or tube decompression. The best evidence exists for SEMS therapy with good short-term results and promising long-term results. There are also data for tube decompression, mainly from the Asian region, with good short-term results. For the left-sided malignant obstruction, published data suggest a superiority of SEMS therapy. It is crucial in decompression of malignant distension to avoid perforation, meaning the technique with the most existing expertise should be used.

\section{Conflict of Interest Statement}

The author has no conflicts of interest to declare.

\section{Funding Sources}

The author received no funding.

\section{Author Contributions}

S.B.: interpretation of data, drafting of the manuscript, critical revision of the manuscript.

References

1 Wells CI, O’Grady G, Bissett IP. Acute colonic pseudo-obstruction: A systematic review of aetiology and mechanisms. World J Gastroenterol. 2017 Aug;23(30):5634-44.

2 Pereira P, Djeudji F, Leduc P, Fanget F, Barth $\mathrm{X}$. Ogilvie's syndrome-acute colonic pseudoobstruction. J Visc Surg. 2015 Apr;152(2):99105.

3 Mathias C, Bannister R. Autonomic failure: a textbook of clinical disorders of the autonomic nervous system. 5 th ed: Oxford University Press; 2013.

4 Vanek VW, Al-Salti M. Acute pseudo-obstruction of the colon (Ogilvie's syndrome). An analysis of 400 cases. Dis Colon Rectum. 1986 Mar;29(3):203-10. 
5 Ross SW, Oommen B, Wormer BA, Walters AL, Augenstein VA, Heniford BT, et al. Acute Colonic Pseudo-obstruction: Defining the Epidemiology, Treatment, and Adverse Outcomes of Ogilvie's Syndrome. Am Surg. 2016 Feb;82(2):102-11.

6 Wegener M, Börsch G. Acute colonic pseudoobstruction (Ogilvie's syndrome). Presentation of 14 of our own cases and analysis of 1027 cases reported in the literature. Surg Endosc. 1987;1(3):169-74.

7 Bode WE, Beart RW Jr, Spencer RJ, Culp CE, Wolff BG, Taylor BM. Colonoscopic decompression for acute pseudoobstruction of the colon (Ogilvie's syndrome). Report of 22 cases and review of the literature. Am J Surg. 1984 Feb;147(2):243-5.

8 Winner M, Mooney SJ, Hershman DL, Feingold DL, Allendorf JD, Wright JD, et al. Incidence and predictors of bowel obstruction in elderly patients with stage IV colon cancer: a population-based cohort study. JAMA Surg. 2013 Aug;148(8):715-22.

9 Jullumstrø E, Wibe A, Lydersen S, Edna TH. Colon cancer incidence, presentation, treatment and outcomes over 25 years. Colorectal Dis. 2011 May; 13(5):512-8.

10 Naveed M, Jamil LH, Fujii-Lau LL, Al-Haddad M, Buxbaum JL, Fishman DS, et al. American Society for Gastrointestinal Endoscopy guideline on the role of endoscopy in the management of acute colonic pseudo-obstruction and colonic volvulus. Gastrointest Endosc. 2020 Feb;91(2):228-35.

11 Tsirline VB, Zemlyak AY, Avery MJ, Colavita PD, Christmas AB, Heniford BT, et al. Colonoscopy is superior to neostigmine in the treatment of Ogilvie's syndrome. Am J Surg. 2012 Dec;204(6):849-55.

12 Rex DK. Colonoscopy and acute colonic pseudo-obstruction. Gastrointest Endosc Clin N Am. 1997 Jul;7(3):499-508.

13 Weusten BL, Barret M, Bredenoord AJ, Familiari P, Gonzalez JM, van Hooft JE, et al Endoscopic management of gastrointestinal motility disorders - part 2: European Society of Gastrointestinal Endoscopy (ESGE) Guideline. Endoscopy. 2020 Jul;52(7):60014.

14 Weusten BL, Barret M, Bredenoord AJ, Familiari P, Gonzalez JM, van Hooft JE, et al. Endoscopic management of gastrointestinal motility disorders - part 1: European Society of Gastrointestinal Endoscopy (ESGE) Guideline. Endoscopy. 2020 Jun;52(6):498515

15 Harrison ME, Anderson MA, Appalaneni V, Banerjee S, Ben-Menachem T, Cash BD, et al.; ASGE Standards of Practice Committee. The role of endoscopy in the management of patients with known and suspected colonic obstruction and pseudo-obstruction. Gastrointest Endosc. 2010 Apr;71(4):669-79.

16 Ponec RJ, Saunders MD, Kimmey MB. Neostigmine for the treatment of acute colonic pseudo-obstruction. N Engl J Med. 1999 Jul; 341(3):137-41.

17 Orlando E, Finelli F, Colla M, Giotto E, Terragni $\mathrm{P}$, Olivero $\mathrm{G}$. [A double-blind study of neostigmine versus placebo in paralytic ileus as a result of surgical interventions]. Minerva Chir. 1994 May;49(5):451-5.
18 van der Spoel JI, Oudemans-van Straaten HM, Stoutenbeek CP, Bosman RJ, Zandstra DF. Neostigmine resolves critical illness-related colonic ileus in intensive care patients with multiple organ failure-a prospective, double-blind, placebo-controlled trial. Intensive Care Med. 2001 May;27(5):822-7.

19 Valle RG, Godoy FL. Neostigmine for acute colonic pseudo-obstruction: a meta-analysis. Ann Med Surg. 2014 Jun;3(3):60-4.

20 Abeyta BJ, Albrecht RM, Schermer CR. Retrospective study of neostigmine for the treatment of acute colonic pseudo-obstruction. Am Surg. 2001 Mar;67(3):265-8.

21 Loftus CG, Harewood GC, Baron TH. Assessment of predictors of response to neostigmine for acute colonic pseudo-obstruction. Am J Gastroenterol. 2002 Dec;97(12):3118-22.

22 Peker KD, Cikot M, Bozkurt MA, Ilhan B, Kankaya B, Binboga S, et al. Colonoscopic decompression should be used before neostigmine in the treatment of Ogilvie's syndrome. Eur J Trauma Emerg Surg. 2017 Aug;43(4): 557-66.

23 Kahi CJ, Rex DK. Bowel obstruction and pseudo-obstruction. Gastroenterol Clin North Am. 2003 Dec;32(4):1229-47.

24 Geller A, Petersen BT, Gostout CJ. Endoscopic decompression for acute colonic pseudoobstruction. Gastrointest Endosc. 1996 Aug; 44(2):144-50.

25 Naef M, Maurer CA, Scheurer U, Seidel K, Langen HP, Sell F, et al. [Idiopathic dilatation of the large intestine (Ogilvie syndromeacute pseudo-obstruction)]. Zentralbl Chir. 1998;123(12):1360-4.

26 Jetmore AB, Timmcke AE, Gathright JB Jr, Hicks TC, Ray JE, Baker JW. Ogilvie's syndrome: colonoscopic decompression and analysis of predisposing factors. Dis Colon Rectum. 1992 Dec;35(12):1135-42.

27 Vogel JD, Feingold DL, Stewart DB, Turner JS, Boutros M, Chun J, et al. Clinical Practice Guidelines for Colon Volvulus and Acute Colonic Pseudo-Obstruction. Dis Colon Rectum. 2016 Jul;59(7):589-600.

28 Kapadia M. Volvulus of the Small Bowel and Colon. Clin Colon Rect Surg. 2017 Feb;30(1): 40-45.

29 Anderson JH, Hole D, McArdle CS. Elective versus emergency surgery for patients with colorectal cancer. Br J Surg. 1992 Jul;79(7): 706-9.

30 Watt AM, Faragher IG, Griffin TT, Rieger NA, Maddern GJ. Self-expanding metallic stents for relieving malignant colorectal obstruction: a systematic review. Ann Surg. 2007 Jul;246(1):24-30.

31 Arezzo A, Passera R, Lo Secco G, Verra M, Bonino MA, Targarona E, et al. Stent as bridge to surgery for left-sided malignant colonic obstruction reduces adverse events and stoma rate compared with emergency surgery: results of a systematic review and meta-analysis of randomized controlled trials. Gastrointest Endosc. 2017 Sep;86(3):416-26.

32 Sloothaak DA, van den Berg MW, Dijkgraaf MG, Fockens P, Tanis PJ, van Hooft JE, et al.; collaborative Dutch Stent-In study group. Oncological outcome of malignant colonic obstruction in the Dutch Stent-In 2 trial. Br J Surg. 2014 Dec;101(13):1751-7.
33 Ceresoli M, Allievi N, Coccolini F, Montori G, Fugazzola P, Pisano M, et al. Long-term oncologic outcomes of stent as a bridge to surgery versus emergency surgery in malignant left side colonic obstructions: a meta-analysis. J Gastrointest Oncol. 2017 Oct;8(5):867-76.

34 Matsuda A, Miyashita M, Matsumoto S, Matsutani T, Sakurazawa N, Takahashi G, et al. Comparison of long-term outcomes of colonic stent as "bridge to surgery" and emergency surgery for malignant large-bowel obstruction: a meta-analysis. Ann Surg Oncol. 2015 Feb;22(2):497-504.

35 Tamini N, Ceresoli M, Aldè S, Carissimi F, Ripamonti L, Nespoli L, et al. Quasi-elective left colectomy after endoscopic colon stenting for obstructive cancer yields comparable oncologic outcome to full-elective operation. Int J Colorectal Dis. 2020 Apr;35(4):633-40.

36 Cao Y, Gu J, Deng S, Li J, Wu K, Cai K. Longterm tumour outcomes of self-expanding metal stents as 'bridge to surgery' for the treatment of colorectal cancer with malignant obstruction: a systematic review and meta-analysis. Int J Colorectal Dis. 2019 Nov;34(11): 1827-38.

37 Amelung FJ, de Beaufort HW, Siersema PD, Verheijen PM, Consten EC. Emergency resection versus bridge to surgery with stenting in patients with acute right-sided colonic obstruction: a systematic review focusing on mortality and morbidity rates. Int J Colorectal Dis. 2015 Sep;30(9):1147-55.

38 van Hooft JE, Veld JV, Arnold D, Beets-Tan RG, Everett S, Götz M, et al. Self-expandable metal stents for obstructing colonic and extracolonic cancer: European Society of Gastrointestinal Endoscopy (ESGE) Guideline - Update 2020. Endoscopy. 2020 May;52(5):389-407.

39 Yoon JY, Jung YS, Hong SP, Kim TI, Kim $\mathrm{WH}$, Cheon JH. Clinical outcomes and risk factors for technical and clinical failures of self-expandable metal stent insertion for malignant colorectal obstruction. Gastrointest Endosc. 2011 Oct;74(4):858-68.

40 Small AJ, Coelho-Prabhu N, Baron TH. Endoscopic placement of self-expandable metal stents for malignant colonic obstruction: long-term outcomes and complication factors. Gastrointest Endosc. 2010 Mar;71(3): 560-72.

41 Abbas MA, Kharabadze G, Ross EM, Abbass MA. Predictors of outcome for endoscopic colorectal stenting: a decade experience. Int J Colorectal Dis. 2017 Mar;32(3):375-82.

42 Suzuki Y, Moritani K, Seo Y, Takahashi T. Comparison of decompression tubes with metallic stents for the management of rightsided malignant colonic obstruction. World J Gastroenterol. 2019 Apr;25(16):1975-85.

$43 \mathrm{Xu}$ J, Zhang S, Jiang T, Zhao YJ. Transanal drainage tubes vs metallic stents for acute malignant left-sided bowel obstruction: A systematic review and meta-analysis. Medicine. 2020 Jan;99(2):e18623.

44 Ribeiro IB, Bernardo WM, Martins BD, de Moura DT, Baba ER, Josino IR, et al. Colonic stent versus emergency surgery as treatment of malignant colonic obstruction in the palliative setting: a systematic review and metaanalysis. Endosc Int Open. 2018 May; 6(5):E558-67. 